\title{
Design of a Distributed Hybrid Electric Propulsion System for a Light Aircraft based on Genetic Algorithm
}

\author{
Siqi Wang1 and J. T. Economou2 \\ Cranfield University, MK43 OAL, UK \\ A. Tsourdos 3 \\ Cranfield University, MK43 OAL, UK
}

\begin{abstract}
Hybrid aircraft is a new attempt for next-generation aircraft, they are environmentally friendly and highly efficient. This paper proposes a new type of hybrid electric propulsion system for light aircraft, which integrated distributed propulsion concept and more electric aircraft concept together to improve aircraft performance. Based on the mission requirements and unique system configuration, all components, including engine, generator and motors are intelligently selected. The sizing problem can be divided into two parts. The power source part applied a non-dominated sorting genetic algorithm to choose components and simultaneously minimized total weight and fuel consumption. The rest of the system used a conventional genetic algorithm, which minimized weight and guaranteed that all selected motors can output enough power. In the end, by applying a simple deterministic energy management strategy, the new system achieved a $12 \%$ fuel consumption reduction.
\end{abstract}

\section{Nomenclature}

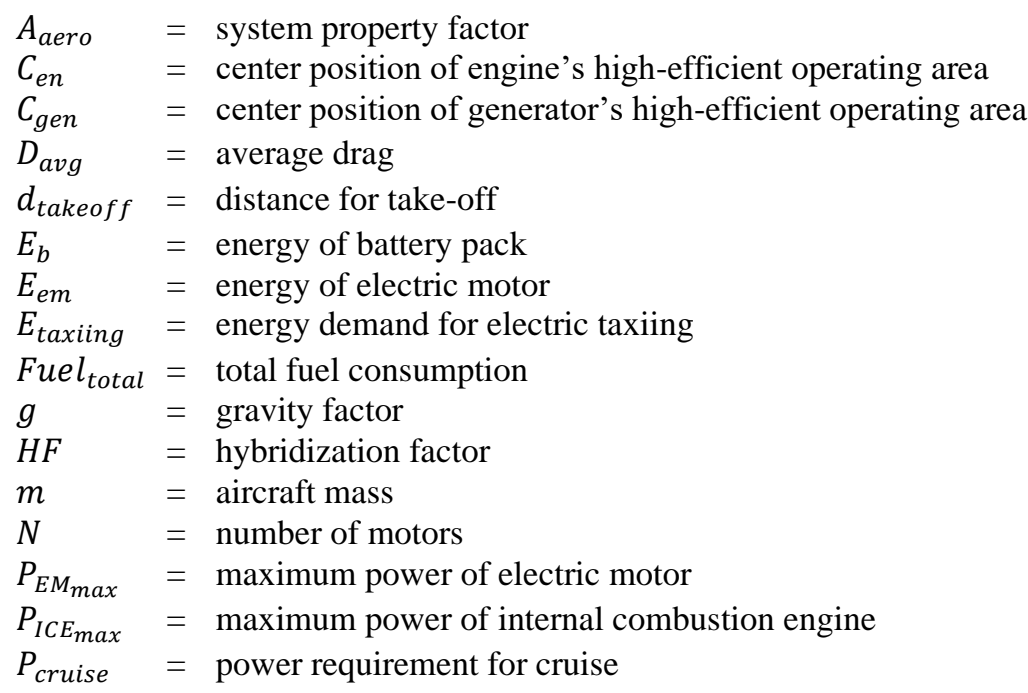

${ }_{1} \mathrm{PhD}$ student, School of Aerospace, Transport, and Manufacturing.

2 Senior Lecturer, Cranfield Defense and Security, Aeromechanical Systems Group Centre for Defense Engineering, The Defense Academy of the United Kingdom, MIET, FHEA.

3 Professor/Head of the Autonomous and Cyber-Physical Systems Centre, School of Aerospace, Transport, and Manufacturing, and AIAA Member. 


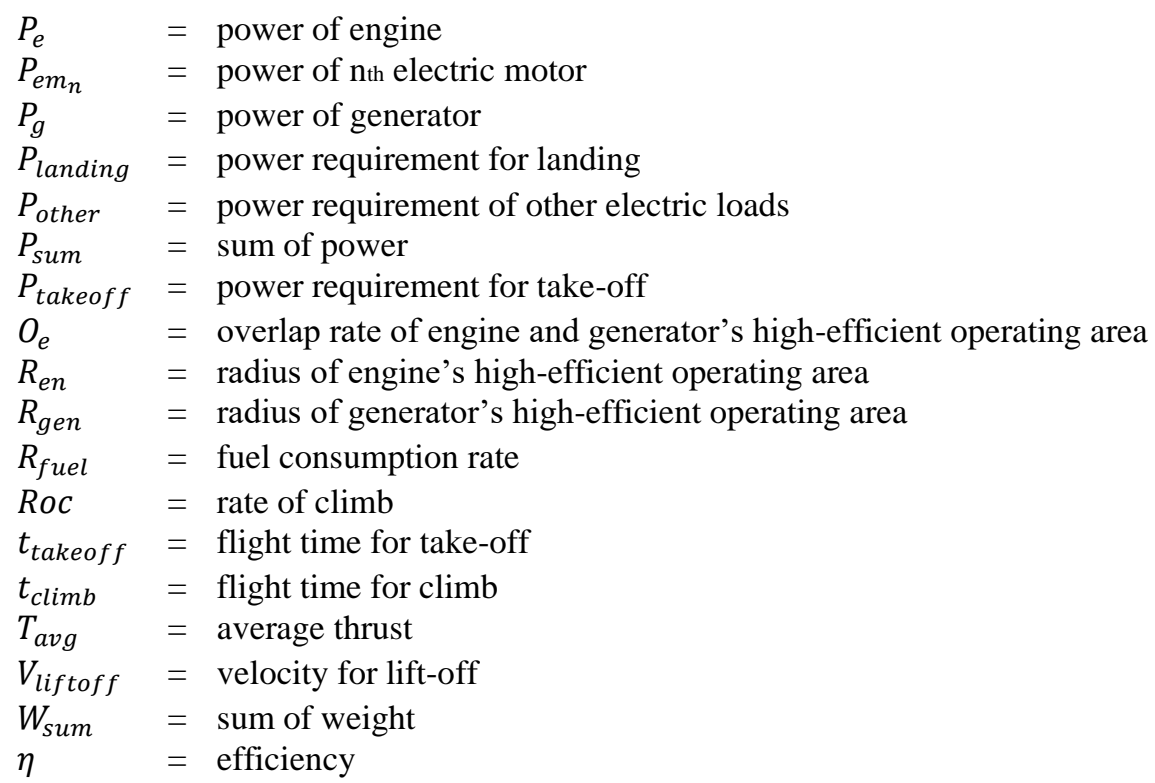

\section{Introduction}

Nowadays, the depletion of fossil fuels and anthropogenic climate change are two crises urged to be mitigated. As one of the root cause is the air transportation industry is reasonable to expect a technology revolution to reduce both fuel consumption and pollutant emissions. In 2011, the Advisory Council for Aeronautic Research and Innovation in Europe (ACARE) developed the 'Flightpath 2050 Goals', aiming to continuously reduce the environmental impact and energy shortage problem in the face of continuing expansion in aviation demand [1]. Later, the International Civil Aviation Organization (ICAO) published a more detailed report on aircraft noise and emissions, which agreed on a comprehensive set of environmental aircraft design standards. At present, energy conservation and environmental protection are two key points of the aviation industry.

Table 1 Hybrid electric aircraft and projects

\begin{tabular}{l|l|c|l|l}
\hline \hline & \multicolumn{1}{|c|}{ Producer } & Pax & \multicolumn{1}{c}{ EAP } & \multicolumn{1}{c}{ Information } \\
\hline DA36 E-star & DA/EADS/Siemens & 1 & Series & Small Wankel ICE,70 kW EM; \\
\hline DA36 E-star 2 & DA/EADS/Siemens & 2 & Series & $30 \mathrm{~kW}$ Wankel ICE, 65 kW EM; \\
\hline Alatus & Cambridge University & 1 & Parallel & $2.8 \mathrm{~kW} \mathrm{ICE,} \mathrm{12} \mathrm{kW} \mathrm{EM;}$ \\
\hline SOUL & Cambridge University & 1 & Parallel & 7.5-8kW ICE, 12 kW EM; \\
\hline Eco-Eagle & Embry-Riddle Aeronautical Uni & 2 & Parallel & 74.5kW ICE, 29.8kW EM; \\
\hline AIRSTART & Airbus/ Cranfield University & - & Parallel & $24 \mathrm{~kW}$ Wankel ICE, 42 kW EM; \\
\hline DEAP & Airbus/Rolls-Royce/ Cranfield Uni & 100 & Turboelectric & Conceptual design \\
\hline E-fan X & Airbus/Rolls-Royce/ Siemens & 146 & Turboelectric & Three Turbofans, 2 MW EM; \\
\hline Quad-Fan & BHL & 180 & Turboelectric \\
\hline SUGAR Freeze & Boeing & 154 & Turboelectric \\
\hline BW-11 & Cranfield University & 800 & Turboelectric \\
\hline Eco-150 & ESAero & 150 & Turboelectric \\
\hline STRAC-ABL & NASA & 154 & Partial Turboelectric \\
\hline N3-X TeDP & NASA & 300 & Turboelectric \\
\hline \hline & \multicolumn{5}{l}{}
\end{tabular}

Up to now, some alternative fuels and low-carbon propulsion technologies have been invented, such as pure electric aircraft. Although using electricity is a promising solution, electric aircraft cannot complete long-duration or high-powerful missions due to the limited storage capacity of a battery pack. Therefore, hybrid electric aircraft become a feasible and expected option for the next-generation aircraft. The research of hybrid aircraft grows rapidly over the past two decades. Based on the type of hybrid propulsion system, hybrid aircraft are commonly categorized into three types: series, parallel and complex. Series hybrid owns the simplest configuration and is firstly 
successfully tested on the aircraft DA36 E-star. Parallel hybrid is proposed later, it has a compacted structure and is higher efficient than series. Some hybrid aircraft and relevant projects are summarized in Table 1[2-11].

As different hybrid systems have different features, the entire designing process is a complex and challenging procedure. From Fig. (1), various choices and combinations can direct to different performance. Therefore, each hybrid propulsion system should be comprehensively considered and specified designed for each aircraft. Regarding system configuration, paper [12] compared series and parallel hybrid, and found that, without considering distant future advancements, the parallel architectures can provide greater range performance than a series hybrid. For component sizing, selecting devices by their power-to-weight ratio and other characteristics is the simplest and popular method [13,14]. Other intelligent sizing methods have been also proposed [15-17]. Paper [16] minimized electricity cost and power loss in its sizing process, by using a multi-objective optimization (MOO) algorithm for a wind/photovoltaic hybrid power supply system. Paper [17] minimized the fuel consumption and achieved a fuelburn reduction of up to $17.6 \%$ by retrofitting of a midscale aircraft.



Fig. 1 System designing process

This paper mainly discusses a design process of an innovative hybrid electric propulsion system, including a selection of hybrid configurations, a system structure optimization, and components sizing. The paper starts with an introduction of hybrid aircraft, followed by a detailed description of the designing process for the new propulsion system. In the third section, methods to improve a conventional series hybrid system is proposed based on different hybrid configurations' characteristics, and the entire system structure is determined by integrating two new design concepts. In section four, requirements for each component are put forward. The optimization model, i.e. objective functions and constraints are demonstrated afterward. Section five introduces candidates of each component, where a comparison of internal combustion engines has been conducted to find the suitable engine type. After that, the algorithm applied for system sizing is mainly talked. As the problem can be divided into two parts, two different types of genetic algorithms are used for each part respectively. Finally, by comparison with the initial benchmark, the performance of the new system is validated at the end of the paper.

\section{Design of the Distributed Hybrid Propulsion System}

The mission requirements and performance criteria are defined next. The performance of the hybrid electric propulsion system is evaluated based on these criteria. The test object of this study is a two-engine light aircraft, Tecnam 2006T, whose specifications are shown in Table 2. The estimated parameters, which are shown at the right column in the table, are the parameters which are calculated based on the plane performance.

Table 2 Characteristics of Tecnam 2006T

\begin{tabular}{|l|c|l|c|}
\hline \multicolumn{2}{|c|}{ Parameters } & \multicolumn{2}{c|}{ Estimated Parameters } \\
\hline Maximum cruise speed $(\mathrm{km} / \mathrm{h})$ & 278 & Wing area $(\mathrm{m} 2)$ & 15 \\
\hline Stall speed $(\mathrm{km} / \mathrm{h})$ & 102 & Lift coefficient & 0.342 \\
\hline Cruise altitude $(\mathrm{m})$ & 4267 & Drag coefficient & 0.023 \\
\hline Take-off distance $(\mathrm{m})$ & 394 & Endurance $(\mathrm{h})$ & 4.25 \\
\hline Landing distance $(\mathrm{m})$ & 349 & Wing loading $\left(\mathrm{kg} / \mathrm{m}_{2}\right)$ & 80 \\
\hline Rate of climb $(\mathrm{m} / \mathrm{s})$ & 5.3 & & \\
\hline Range $(\mathrm{km})$ & 1239 & & \\
\hline Max take-off weight $(\mathrm{kg})$ & 1230 & & \\
\hline Empty weight $(\mathrm{kg})$ & 819 & & \\
\hline
\end{tabular}


Longer endurance is a common design objective. In addition, considering also the environmental, a lower fuel consumption rate and fewer emissions are two additional goals for the new system. Therefore, an efficient and environmentally friendly hybrid electric propulsion system is the target for this research.

The first step for designing a hybrid electric propulsion system is to define the configuration. As a reference, three hybrid configurations and their characteristics are shown in Table 3. Amongst them, series hybrid systems decouple the engine from the power demand, which provides an opportunity to allow the engine continuously operating in high-efficient or less-emission area. Parallel hybrid systems are higher efficient than series, due to the engine output straightly propel the propeller without an electricity transformation. Complex hybrid systems have various types, and each of them has its own features. Due to complex hybrid systems mechanically link the engine and the propeller, the complex hybrid will be temporarily categorized into parallel in the rest of the paper.

Table 3 Different hybrid configurations and their characteristics



Hybridization factor, $H F$, is a useful factor to examine hybrid propulsion systems [18]. As Eq. (1), for both series and parallel hybrid, the denominator is the maximum power demand. Therefore, the engine capacity, $P_{I C E_{\max }}$, becomes the only parameter to decide $H F$. A comparison can be conducted for a series and parallel system which has a same $H F$. For example, assuming $H F=0.5$, the engine and motor capacity for these two systems are shown in Eq. (2) and Eq. (3) respectively. When the instant mission power requirement is $0.5 P_{\max }$ and the battery pack is depleted, series systems cannot work as efficient as parallel. Parallel systems use engine to drive a propeller, while series systems firstly transform engine output to electricity and then use motor to turn the propeller. Since energy loss is unavoidable during energy conversions and the extra device, generator, heavy the entire system, parallel hybrid systems are more efficient under this assumption. However, when the power demand is still $0.5 P_{\max }$ but the battery pack is not depleted, the performance may be different. Series systems can arrange the engine to stably operate at its highest-efficient point, while parallel systems have to regulate engine's rotation speed since it is mechanically linked to the propeller. As a result, it is hard to define which category is more efficient.

$$
H F=\left\{\begin{array}{cc}
\frac{\left(P_{E M_{\max }}-P_{I C E_{\max }}\right)}{P_{E M_{\max }}} & \text { series } \\
\frac{P_{E M_{\text {max }}}}{P_{E M_{-} \max }+P_{I C E \_\max }} & \text { parallel/complex }
\end{array}\right.
$$




$$
\begin{array}{lll}
\text { Series: } & P_{I C E_{\max }}=\frac{1}{2} P_{\max }, & P_{E M_{\max }}=P_{\max } \\
\text { Parallel: } & P_{I C E_{\max }}=\frac{1}{2} P_{\max }, & P_{E M_{\max }}=\frac{1}{2} P_{\max }
\end{array}
$$

This study selected the series hybrid configuration as a baseline since it has a unique decoupled structure. However, as mentioned before, series systems have drawbacks. To offset them, the concept of a common-core multi-fans (CMF) distributed propulsion system and more electric aircraft (MEA) are integrated into the designing. Distributed propulsion concept refers to using multiple small propellers to blow the wing. Paper [19] proves that a distributed propulsion system has a better lift property for aircraft. MEA means an aircraft system transforms the engine output to electricity firstly and then use generated electricity to power ailerons etc. It removes redundant battery packs and increases the usage rate of each propulsion component. Therefore, the designed system is a distributed series hybrid electric propulsion system (DSHEPS), and the flowchart is shown in Fig (2).

There are many advantages to this design. At first, it is a decoupled structure which allows the engine to run isolated. The decoupled configuration not only benefits the engine performance but also electrified the whole propulsion system. Secondly, it improves lift property by blowing more wind above the wing [20]. Thirdly, it reduces engine size. Aircraft engines are always over-sized. For example, engines of a twin-engines aircraft must be sized as twice thrust as required in case of an engine-failure scenario. However, when applying multi-propulsors, the rest of the propulsors can output more power when one propulsor failure. It is not necessary to over-size engines or other propulsors.

For easily understand, the system can be divided into three parts: power sources, other loads and propulsion loads. The first part is the power source of the entire system, which includes an engine, a generator, and a battery pack. The second part consists of outside electrical loads, such as an electric taxiing system. Electric taxiing refers to an aircraft uses a motor to directly drive wheels during taxiing stage instead of using propellers [21]. The new taxiing method is more efficient and allows to switch off engine earlier due to the battery pack can provide energy for taxiing. The third part contains all propulsors, mainly for energy output. It is a symmetric structure, i.e. all motors are placed symmetrically.

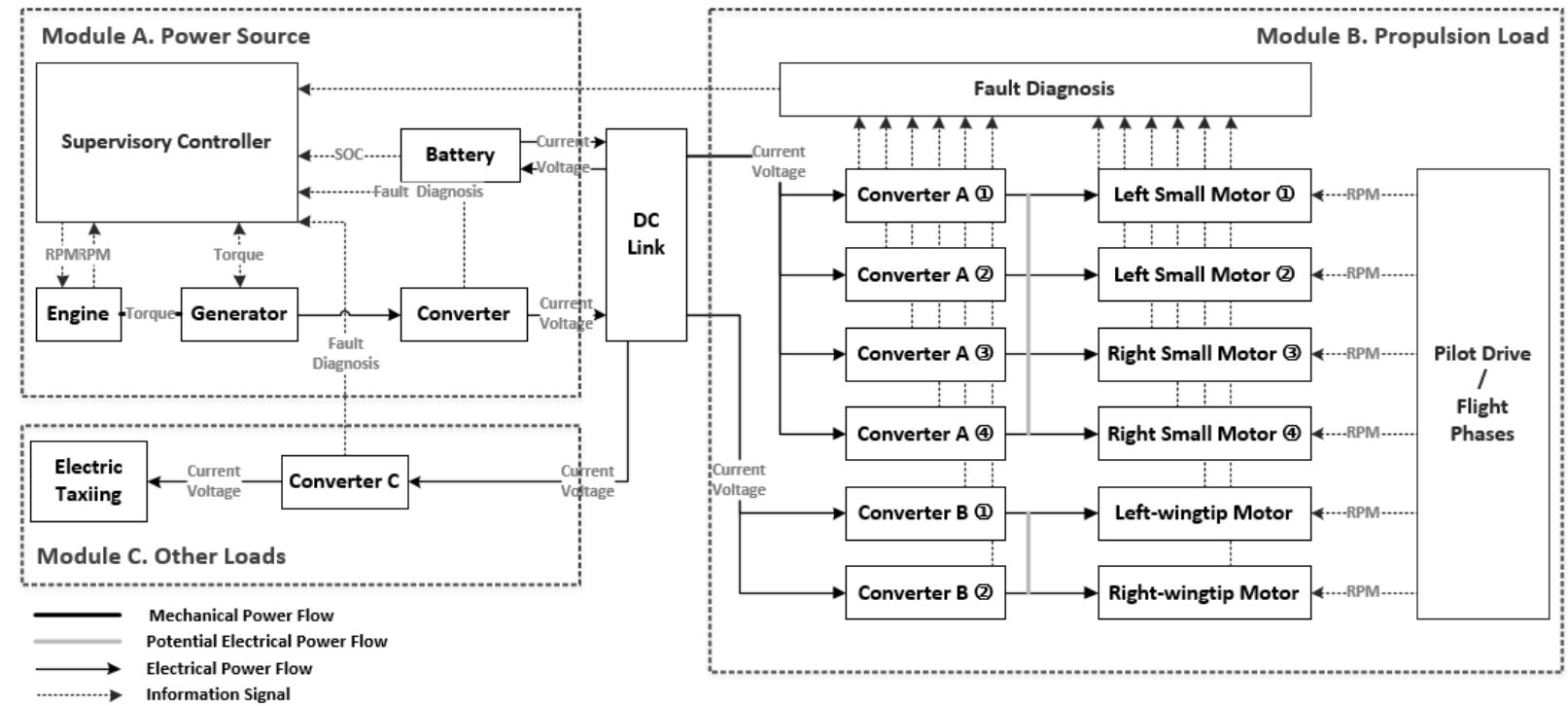

Fig. 2 Entire DSHEPS configuration

\section{Requirements of System Sizing Problem}

The designed system services for a light aircraft. Therefore, the mission gives an instruction for basic requirements of entire system. One typical mission consists of taxiing, taking-off, climbing, cruising, descending, landing and taxiing, total eight flight stages. Taking-off costs as twice much as cruise required which indicates the maximum power requirement, and cruising, as the main performance during the flight, shows the lowest power demand. Assuming cruising is steady without any acceleration in any direction, the minimum power requirement can be determined by the vertical and longitudinal force equations. All equations are listed in Fig. 4. 
Based on the shown configuration, a table of requirements for each component could be determined, shown as Fig. (3). Similarly, since DSHEPS is a decoupled system, the sizing process is divided into two parts: power source and power loads.



Fig. 3 System Sizing Process

\section{A. Power Source}

Power source part includes an engine, a generator and a battery pack. From the configuration, the performance of the battery pack, i.e. whether charging or discharging, is decided by the engine operational condition. Namely, the battery pack operates passively and its output should equal to the difference between mission requirement and engine output. Therefore, the engine pack is the most important component of this part. To find a suitable engine, the author has proposed a new sizing method via batteries' state-of-charge (SOC) based parametrization criteria. It found that the engine whose optimal output is around 1.2 times of the average value of power requirement, $1.2 P_{\text {cruise }}$, will lead to a better battery performance, as shown in Eq. (6) [21].

The selected engine is small and it is not capable to generate enough power for high-powerful missions, such as take-off or climbing. Then, the battery pack should provide the rest of the required energy. Namely, the capacity of the battery pack must be larger than the difference between the highest power requirement and engine capacity, as seen in Eq. (9). In addition, if the battery pack has enough energy for electric taxiing, the engine can be switched off soon after a successful landing. It reduces engine operation time and decreases the amount of consumed fuel. Therefore, another criterion of the battery pack is Eq. (8), in which the remaining energy of the battery pack after landing, should be more than the electric taxiing demand. The last consideration for the battery pack is an emergency scenario. In case of engine failure, the battery pack should be capable to support a 5-10 min flight for a forced landing, i.e. Eq. (10). Batteries should guarantee enough energy output and therefore result in a safe flight.

The generator and engine are tied tightly and work together. Therefore, the generator's maximum capacity should be above the engine output, as shown as Eq. (7). The objective functions of part A are: 


$$
\begin{aligned}
& \min J_{1}=W_{\text {sum }} \\
& \min J_{2}=\int_{0}^{t} R_{\text {fuel }}
\end{aligned}
$$

While the constraints are:

$$
\begin{aligned}
& \text { opt } P_{e} \geq 1.2 P_{\text {cruise }} \\
& \max _{g} \geq \max _{e} \\
& E_{\text {taxiing }} \leq \max _{b} \\
& \left(P_{\text {takeoff }}-\text { opt } P_{e} \cdot \eta-P_{\text {other }}\right) \cdot\left(t_{\text {takeoff }}+t_{\text {climb }}\right)<\max E_{b} \\
& E_{\text {em }}=\int_{0}^{t} P d t \approx P t \leq \frac{1}{2}\left(P_{\text {cruise }}+P_{\text {landing }}+P_{\text {other }}\right) \cdot t \leq \max E_{b}
\end{aligned}
$$

\section{B. Propulsion Load}

Part B consists of motors and converters. The number of motors $N$ should be an even number due to it is a symmetric configuration. If rated voltages of motors are the same as the main grid, converters will not be necessary unless there are special requirements. However, from searching the open-domain literature, there is no study regarding the relationship between the number of motors and aircraft aerodynamic properties. Unless the designed system conduct a wind tunnel test, it cannot straightly say which kind of configuration is better than others. Therefore, this study assumes a positive factor $A_{\text {aero }}$ to indicate that distributed propulsion is an improvement to conventional one. It is a constant number rating the distribution level. Therefore, the objective function of part $\mathrm{B}$ is the sum of total weight and the designed factor. Due to the uncertainty of the factor $A_{\text {aero }}$, its maximum value has been scaled to half of the maximum weight. Above all, the objective function and constraint could be written as:

$$
\begin{aligned}
& \min _{3}=W_{\text {sum }}+A_{\text {aero }} \\
& \max P_{\text {sum }}=\sum_{1}^{N} \max P_{\text {em }} \geq P_{\text {takeoff }}
\end{aligned}
$$

\section{Aircraft Performance}

Although DSHEPS is a brand-new design, performance criteria of original aircraft cannot be sacrificed. In other words, the new system should guarantee that DSHEPS has the same or better rate of climb and take-off distance, i.e.

$$
\begin{aligned}
& \operatorname{Roc}^{\prime} \approx \frac{P_{\text {climb }}-P_{\text {cruise }}}{m \cdot g} \geq R o c \\
& d_{\text {takeoff }}^{\prime} \approx \frac{m \cdot V_{\text {liftoff }}^{2}}{2\left(T_{\text {avg }}-D_{\text {avg }}\right)} \leq d_{\text {takeoff }}
\end{aligned}
$$

\section{System Components}

Assuming cruise is steady and no acceleration, the power requirement for a common flight can be determined. Calculations are mentioned in paper [17, 21]. Fig. (4) shows the power demand for a typical flight, which is the test mission of the new propulsion system. Here, the power requirement for the cruise is $P_{\text {cruise }}=60 \mathrm{~kW}$ and the flight endurance is $60 \mathrm{~min}$. 


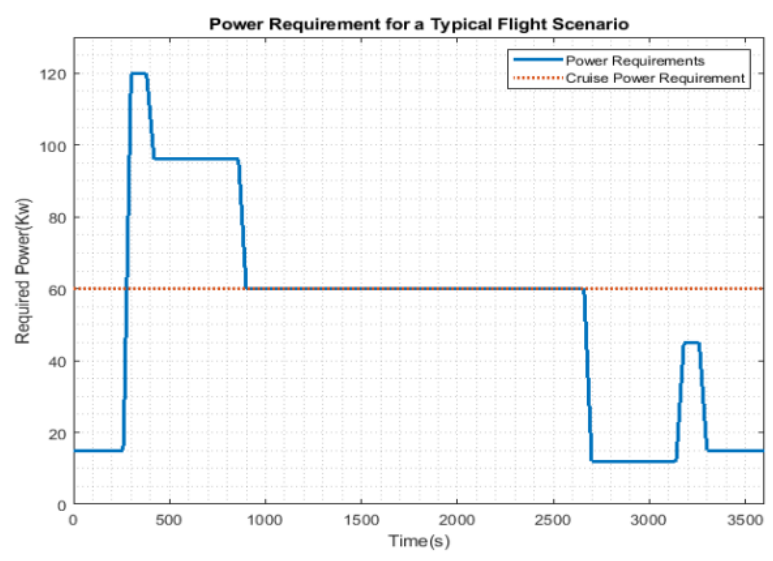

Fig. 4 Power requirement of a typical flight

\section{A. Engine}

Common aero engines are internal combustion engines (ICE) and gas turbines. ICEs can generate energy up to $2000 \mathrm{~kW}$, and gas turbines typically produce 100-400 MW. From the ideal propulsive efficiencies map in the book [22], when the Mach number is less than $0.3(367 \mathrm{~km} / \mathrm{h})$, the efficiency of ICEs is higher than other propulsors'. Therefore, ICEs are more frequently applied in small, low-speed aircraft, especially for less than 400kW power demand.

About 80 different engines are selected as candidates. The weight, volume, price, and power of each candidate are shown as Fig. (5). The left figure of Fig. (5) shows the relationship between engine weight and capacity. There are six categories of engines, including 1-4 cylinder piston engines, rotary engines, and turboshaft engines, and each of them is marked by different colors. From the figure, it can be found that rotary engines have the best power-toweight ratios, while turboshaft engines show great performance in the high powerful area. For analyzing engine volume and price, different sized engines from three companies are elected. From the right figure, the volume linearly increases with capacity, but the price shows exponential growth.


Fig. 5 Engine analysis

\section{B. Battery}

The type, capacity, and normal voltage are essential parameters for a battery pack. At present, common rechargeable batteries are Lead-acid battery, Nickel-Cadmium (Ni-Cd) battery, Nickel-Metal Hydride (Ni-MH) battery, Lithium-Ion (Li-ion) battery, and Lithium-Ion Polymer (Li-Po) battery. Their energy densities are shown in Table 4 [23]. Amongst them, Li batteries (Li-ion and Li-Po) are superior since they have higher energy-to-weight ratios and excellent performance. They can charge faster, last longer and be packed in a thinner package compared to other batteries. Li-ion and Li-Po owns the same chemical reaction with different cathode and electrolyte. Li-ion is 
older than Li-Po, but it is still popular due to low price and easy maintenance. Li-Po is regarded as a more advanced battery which possesses slightly higher energy and thinner volume. Therefore, this study utilized Li-Po batteries as the battery pack. Due to the voltage and capacity vary proportionally by adding or reducing the number of cells, the battery pack's weight could be estimated by the energy-to-weight density and cell number. Therefore, the number of cells is the variable we need to determine.

Table 4 Batteries energy density [23]

\begin{tabular}{|l|c|c|c|c|c|}
\hline & Lead-acid & Ni-Cd & Ni-MH & Li-ion & Li-Po \\
\hline Energy density $(\mathrm{wh} / \mathrm{kg})$ & $33-42$ & 30 & 100 & $100-265$ & $100-265$ \\
\hline
\end{tabular}

\section{Motor and Generator}

Through the interaction between the magnetic field and current-carrying conductors, motors transform electric energy into mechanical energy, generators vice versa. Different classifications of motors are summarized in Fig. (7). The permanent magnet synchronous motor (PMSM) and brushless direct current motor (BLDC) are two popular motors due to their output have less fluctuation. Based on the power-to-weight table of electric motors/electromotive generators in [24], motors/generators which possessing high power-to-weight density are candidates.

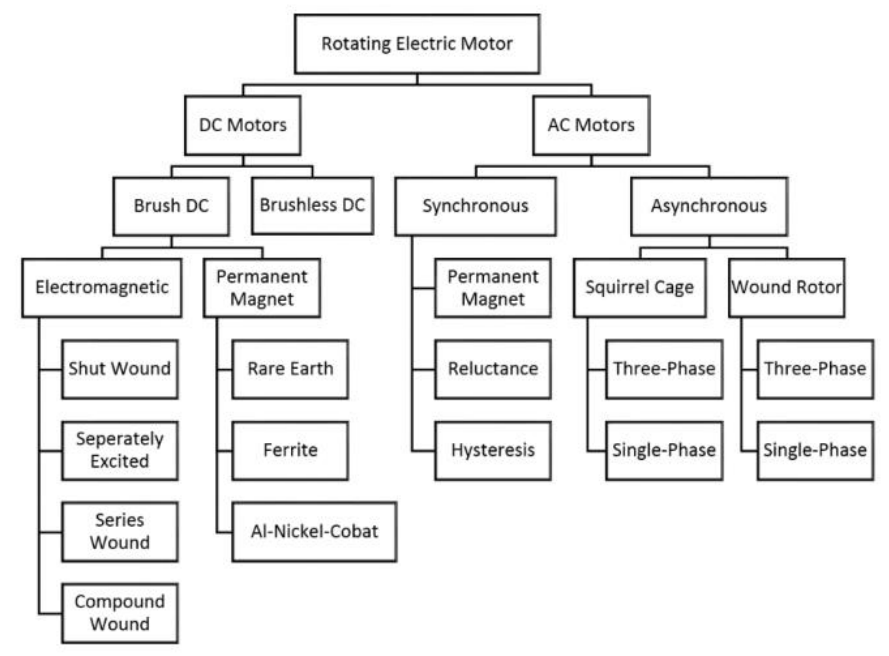

Fig. 6 Motor categories

\section{Genetic Algorithm}

From the previous section, there are two objectives of Part A: less weight and higher efficiency. Due to it is a multi-objective optimization problem, the fast non-dominated sorting algorithm-II (NSGA-II) [25] is applied here to find a better component combination. The NSGA-II is a heuristic method based on Pareto ranking and crowding distance approaches. It firstly calculates objective values and sorts population according to the non-domination. The offspring population is mainly generated by high-ranking individuals with mutation and crossover behaviors.

Table 5 Pseudocode of NSGA-II for Part A

Algorithm Pseudocode for Part A

Input: information of component candidates;

Initialization: randomly generate population $\boldsymbol{P}$, and extract information;

Constraints handling: delete infeasible individuals and replaced by feasible ones;

for $\mathrm{i}=\mathrm{I}: N P$ (or while not Termination Condition)

Select parent population;

Find the matched engine and generator based on overlap maps; 
Crossover + Mutation $\rightarrow$ offspring $Q$, let $R=P \cup Q$

Constraints handling;

Evaluate the objective value: total weight and total fuel consumption for a typical flight scenario;

Non-dominated sorting and calculating crowding distance;

Tournament Selection $\rightarrow$ next generation $P$;

end

For the problem of Part A, an extra archive is added to find matched engine and generator. This archive contains the information of the brake-specific fuel consumption (BSFC) map and efficiency map of each engine and generator. From these maps, the feasible and high-efficient operating area of each candidate could be obtained. Therefore, if the best operating area of an engine and generator is the same, a group by these two components will be a good choice for the designed system. Therefore, a new parameter $O_{e}$, the overlap rate of engine and generator high-efficient area has been introduced to Part A sizing problem. Assuming each high-efficient operating area is a circular whose center is $C_{e n}, C_{g e n}$ with radius $R_{e n}, R_{g e n}$ respectively, the overlap rate could be estimated by:

$$
O_{e}=\frac{R_{e n}+R_{g e n}}{\left|C_{e n}-C_{g e n}\right|}
$$

Gears can change the Revolutions Per Minute (RPM) and torque. If there is a suitable gear connecting engine and generator, the overlap rate may increase but the system will have an extra component. For this problem, a gearbox will be added if it can increase the overlap rate.

Therefore, there are five genes in one chrome: the index of engine candidates, the index of generator candidates, the cell number of the battery pack, and engine operating point (RPM and torque) respectively. Specifications, such as the maximum power, weight, high-efficient operating area are imported according to the component index in each chrome. Since there are some basic requirements for the designed system, from Eq. (6) to Eq. (10), the generated population should satisfy these constraints, i.e. infeasible chromes would be replaced by feasible ones. In this problem, tournament method is used to select parent population, and $O_{e}$ is calculated and recorded during the sorting process. The pseudocode is shown in Table 5.



Fig. 7 Flowchart of genetic algorithm 
The question of Part B is a single-objective problem so that it can use a conventional genetic algorithm to select the system component. The objective function and constraint are shown in Section four. The flowchart of the applied genetic algorithm is shown in Fig. 7.

$$
\begin{aligned}
& F C R=\frac{B S F C @ \text { oprating point }}{B S F C @ \text { the most-efficient point }} \\
& \text { Fuel }_{\text {total }}=\int_{0}^{t} F C R \\
& d_{\text {takeoff }}^{\prime} \approx \frac{m \cdot V_{\text {liftoff }}^{2}}{2\left(T_{\text {avg }}-D_{\text {avg }}\right)} \leq d_{\text {takeoff }} \\
& \text { Roc } \approx \frac{P_{\text {climb }}-P_{\text {cruise }}}{m \cdot g}
\end{aligned}
$$

Part A and Part B are parallel problems. The two problems run separately and consequently deliver solutions to the final calculation. The result of Part A is a Pareto front, which is a series of non-dominated solutions with lower weight and low fuel consumption rate. Part B has only one objective, thus the result of Part B is one solution. Combined results of Part A and Part B, a series of feasible solutions are determined. To examine the calculated solutions, some of the aircraft performances are estimated. The first and most important parameter is the total fuel consumption. Since engine candidates are from different companies to allow good comparisons, it is more reasonable to calculate the use of a fuel consumption rate for the comparison rather than using the total fuel consumption amount. The fuel consumption rate (FCR) mentioned here is the ratio of the brake-specific fuel consumption (BSFC) at the operating point to that at the most efficient operating point, as Eq. (16) shows. As a result of using this parameter, the total fuel consumption amount is the integrated FCR. The second important characteristic is the aircraft rate of climb. Here, the power requirement of the cruise mode is used to present the power overcoming drag. The last performance parameter is the take-off distance. Neglecting the rolling resistance and fraction, the take-off distance could be estimated by Eq. (14). Therefore, the comparison between the prototype and DSHPES aircraft is shown in the table.

Table 6 Comparison of a conventional system and hybrid system

\begin{tabular}{llcc}
\hline & & Tecnam P2006T & DSHEPS \\
\hline Max Propulsion Power & & $147 \mathrm{kw}$ & $284 \mathrm{kw}$ \\
System Power & Engine max power & $147 \mathrm{kw}$ & $135 \mathrm{kw}$ \\
& Generator continuous power & 0 & $75 \mathrm{kw}$ \\
& Motor power & 0 & $284 \mathrm{kw}$ \\
Weight & Battery capacity & 0 & $7.5 \mathrm{kwh}$ \\
& Engine weight & $130 \mathrm{~kg}$ & $42 \mathrm{~kg}$ \\
& Generator weight & 0 & $20 \mathrm{~kg}$ \\
& Motor weight & 0 & $66 \mathrm{~kg}$ \\
Performance & Battery weight & $10 \mathrm{~kg}$ & $28 \mathrm{~kg}$ \\
& Total weight & $140 \mathrm{~kg}$ & $156 \mathrm{~kg}$ \\
& Rate of climb & $5.3 \mathrm{~m} / \mathrm{s}$ & $5.9 \mathrm{~m} / \mathrm{s}$ \\
& Take-off distance & $394 \mathrm{~m}$ & \\
& Average FCR & 4.1 & 3.6 \\
\hline
\end{tabular}

\section{Conclusion}

This paper mainly describes a process about a distributed aircraft propulsion system design. It starts at choosing the conventional series hybrid system as the benchmark based on an analysis of common hybrid systems. Thereafter, it adopts a DP and MEA concept to improve the conventional hybrid aircraft system. With the proposed system configuration, the components are sized by different genetic algorithms and as a result the optimized configuration achieves a $12 \%$ fuel consumption reduction.

\section{References}

[1] Advisory Council for Aeronautic Research and Innovation, "Protecting the environment and the energy supply," 2011. [Online], URL: https://www.acare4europe.org/sria/flightpath-2050-goals/protecting-environment-and-energy-supply-0

[2] C. Friedrich and P. A. Robertson, "Hybrid-Electric Propulsion for Aircraft," Journal of Aircraft, 2014. doi: 10.2514/1.C032660 
[3] J.B.Heywood, Internal Combustion Engine Fundamental, New York: McGraw-Hill, 1988.

[4] P.Pillay and K.Ramu, "Modelling of permanent magnet motor drives," in Robotics and IECON'87 Conferences. International Society for Optics and Photonics, 1987. doi: $10.1109 / 41.9176$

[5] National Aeronautics and Space Administration, "Overview of Subsonic Fixed Wing Project: Technical Challenges for Energy Efficient, Environmentally Compatible Subsonic Transport Aircraft," 3rd NASA Glenn Propulsion Control \& Diagnostics Workshop, Cleveland OH, 2012.

[6] J. R. Welstead and J. L. Felder, "Conceptual Design of a Single-Aisle Turboelectric Commercial Transport with Fuselage," in 54th AIAA Aerospace Sciences Meeting, 2016. doi: $10.2514 / 6.2016-1027$

[7] M. D. Moore, "Distributed Electric Propulsion (DEP) Aircraft," National Aeronautics and Space Administration, 2014. URL: https://aero.larc.nasa.gov/files/2012/11/Distributed-Electric-Propulsion-Aircraft.pdf

[8] M. K. Bradley and C. K. Droney, "Subsonic Ultra Green Aircraft Research Phase II: N+4 Advanced Concept Development," National Aeronautics and Space Administration, California, 2012.

URL: https://ntrs.nasa.gov/archive/nasa/casi.ntrs.nasa.gov/20120009038.pdf

[9] Siemens, Diamond Aircraft and EADS, "World's first serial hybrid electric aircraft to fly at Le Bourget," Siemens, Diamond Aircraft and EADS, Munich, 2011.

[10] Siemens, Airbus and Rolls-Royce, "Airbus, Rolls-Royce, and Siemens team up for electric future," London, 2017.

[11] P. Robertson, "Low Carbon Recreational Flying - The Hummingbird Electric Microlight".

[12] T. S. Dean, G. E. Wroblewski and P. J. Ansell, "Mission Analysis and Component-Level Sensitivity Study of HybridElectric General Aviation Propulsion Systems," in AIAA Aerospace Sciences Meeting, Kissimmee, 2018. doi: $10.2514 / 6.2018-1749$

[13] C.Friedrich and P.A.Robertson, "Design of a Hybrid-Electric Propulsion System for Light Aircraft," in AIAA Aviation Technology, Integration and Operation Conference, Atlanta, 2014. doi: 10.2514/6.2014-3008

[14] J. Koster, C. Humbargar, E. Serani, A. Velazco, D. Hillery and L. Makepeace, "Hybrid Electric Integrated Optimized System Design of a Hybrid Propulsion System for Aircraft," in 9th AIAA Aerospace Sciences Meeting, Orlando, 2011. doi: $10.2514 / 6.2011-1011$

[15] C. Pornet, C. Gologan, P. Vratny, A. Sertz, O. Schmitz and A. T. I. a. M. Hornung, "Methodology for Sizing and Performance Assessment of Hybrid Energy Aircraft," Journal of Aircraft, vol. 52, no. 1, January-February 2015. doi: 10.2514/1.C032716

[16] A. Abdelkader, A. Rabeh, D. M. Ali and J. Mohamed, "Multi-objective genetic algorithm based sizing optimization of a stand-alone wind/PV power supply system with enhanced battery/supercapacitor hybrid energy storage," Energy, pp. 351363, August 2018. doi: 10.1016/j.energy.2018.08.135

[17] Y. Xie, A. Savvaris and A. Tsourdos, "Sizing of hybrid electric propulsion system for retrofitting a mid-scale aircraft using non-dominated sorting genetic algorithm," Aerospace Science and Technology, no. 82-83, pp. 323-333, September 2018.

doi: 10.1016/j.ast.2018.09.022

[18] SM.Lukic and A.Emadi, "Effects of Drivetrain Hybridization on Fuel Economy and Dynamic Performance of Parallel Hybrid Electric Vehicles," vol. 53, no. 2, pp. 385-389, 2004. doi: 10.1109/TVT.2004.823525

[19] J. Welstead and J. L. Felder, "Conceptual Design of a Single-Aisle Turboelectric Commercial Transport with Fuselage Boundary Layer Ingestion," 54th AIAA Aerospace Sciences Meeting, 2016. doi: 10.2514/6.2016-1027

[20] J. Hoelzen, Y. Liu, B. Bensmann, C. Winnefeld, A. Elham, J. Friedrichs and R. Hanke-Rauschenbach, "Conceptual Design of Operation Strategies for Hybrid Electric Aircraft," Energies, vol. 11, 2018. doi: 10.3390/en 11010217

[21] S.Wang, J.T.Economou and A.Tsourdos, " Indirect engine sizing via distributed hybrid-electric unmanned aerial vehicle state-of-charge-based parametrisation criteria. Proceedings of the Institution of Mechanical Engineers, Part G: Journal of Aerospace Engineering. doi: $10.1177 / 0954410019843722$

[22] D. Howe, Aircraft Conceptual Design Synthesis, Wiley, 2014, p. 62.

[23] Wikipedia contributors, "Comparison of commercial battery types," 16 December 2018. [Online]. Available: https://en.wikipedia.org/w/index.php?title=Comparison_of_commercial_battery_types\&oldid=873978689. [Accessed 7 January 2018].

[24] Wikipedia contributors, "Power-to-weight ratio," Wikipedia, The Free Encyclopedia., 1 January 2019. [Online]. 
Available: https://en.wikipedia.org/wiki/Power-to-weight_ratio. [Accessed 1 January 2019].

[25] K. Deb, A. Pratap, S. Agarwal and T. Meyarivan, "A fast and elitist multiobjective genetic algorithm: NSGA-II," in IEEE Transactions on Evolutionary Computation, vol. 6, no. 2, pp. 182-197, April 2002. doi: $10.1109 / 4235.996017$ 
2019-08-16

\section{Design of a distributed hybrid electric propulsion system for a light aircraft based on genetic algorithm}

Economou, John T.

AIAA

Wang S, Economou JT, Tsourdos A. (2019) Design of a distributed hybrid electric propulsion system for a light aircraft based on genetic algorithm. In: AIAA Propulsion and Energy 2019

Forum, 19-22 August 2019, Indianapolis, USA

https://doi.org/10.2514/6.2019-4305

Downloaded from Cranfield Library Services E-Repository 